University of Nebraska - Lincoln

DigitalCommons@University of Nebraska - Lincoln

$2-1-2006$

\title{
Farnesol-induced apoptosis in Aspergillus nidulans reveals a possible mechanism for antagonistic interactions between fungi
}

\author{
Camile P. Semighini \\ University of Nebraska-Lincoln \\ Jacob M. Hornby \\ Lewis-Clark State College, jmhornby@lcsc.edu \\ Raluca Dumitru \\ University of Nebraska-Lincoln \\ Kenneth W. Nickerson \\ University of Nebraska-Lincoln, knickerson1@unl.edu \\ Steven D. Harris \\ University of Nebraska-Lincoln, Steven.Harris@umanitoba.ca
}

Follow this and additional works at: https://digitalcommons.unl.edu/plantpathpapers

Part of the Plant Pathology Commons

Semighini, Camile P.; Hornby, Jacob M.; Dumitru, Raluca; Nickerson, Kenneth W.; and Harris, Steven D., "Farnesol-induced apoptosis in Aspergillus nidulans reveals a possible mechanism for antagonistic interactions between fungi" (2006). Papers in Plant Pathology. 93.

https://digitalcommons.unl.edu/plantpathpapers/93

This Article is brought to you for free and open access by the Plant Pathology Department at DigitalCommons@University of Nebraska - Lincoln. It has been accepted for inclusion in Papers in Plant Pathology by an authorized administrator of DigitalCommons@University of Nebraska - Lincoln. 


\section{Farnesol-induced apoptosis in Aspergillus nidulans reveals a possible mechanism for antagonistic interactions between fungi}

\author{
Camile P. Semighini ${ }^{1,2}$, Jacob M. Hornby ${ }^{4}$, \\ Raluca Dumitru ${ }^{3}$, Kenneth W. Nickerson ${ }^{3}$, and \\ Steven D. Harris ${ }^{1,2, *}$
}

\begin{abstract}
${ }^{1}$ Plant Science Initiative, ${ }^{2}$ Department of Plant Pathology, and ${ }^{3}$ School of Biological Sciences, University of Nebraska-Lincoln, Lincoln, NE, USA.
\end{abstract}

${ }^{4}$ Division of Natural Sciences and Mathematics, Lewis-Clark State College, Lewiston, ID, USA.

*Corresponding author. Email sharri1@unlnotes.unl.edu; Tel. 402 472-2938; Fax 402 472-3139.

\begin{abstract}
The dimorphic fungus Candida albicans secretes farnesol, which acts as a quorum-sensing molecule and prevents the yeast to mycelium conversion. In this study we examined the effect of farnesol in the filamentous fungus Aspergillus nidulans. We show that externally added farnesol has no effect on hyphal morphogenesis; instead, it triggers morphological features characteristic of apoptosis. Additional experiments suggest that mitochondria and reactive oxygen species (ROS) participate in farnesol-induced apoptosis. Moreover, the effects of farnesol appear to be mediated by the FadA heterotrimeric $G$ protein complex. Because $A$. nidulans does not secrete detectable amounts of farnesol, we propose that it responds to farnesol produced by other fungi. In agreement with this notion, growth and development were impaired in a farnesol-dependent manner when $A$. nidulans was co-cultivated with C. albicans. Taken together, our data suggest that farnesol, in addition to its quorum-sensing function that regulates morphogenesis, is also employed by $C$. albicans to reduce competition from other microbes.
\end{abstract}

\section{Introduction}

Candida albicans is one of the most frequently isolated fungal pathogens of humans. It is a common cause of nosocomial infections, especially in immunocompromised individuals (Kullberg and Filler, 2002). An important feature of $C$. albicans is its ability to grow as hyphae, pseudohyphae or budding yeasts. Because monomorphic mutants are typically avirulent (Lo et al., 1997;
Braun et al., 2000), it is believed that the yeast to mycelium dimorphism is important for pathogenicity (Saville et al., 2003). In this context, C. albicans produces farnesol as an extracellular quorum-sensing molecule (Hornby et al., 2001). Upon accumulation above a threshold level, farnesol prevents the yeast to mycelium transition and causes the culture to grow as actively budding yeasts without influencing cellular growth rates (Hornby et al., 2001). Farnesol has also been found to block biofilm formation by C. albicans (Ramage et al., 2002). By contrast, in the related yeast Saccharomyces cerevisi$a e$, farnesol exhibits a growth inhibitory effect by promoting mitochondrial generation of reactive oxygen species (ROS) (Machida et al., 1998; 1999). Farnesol triggers hyperpolarization of the mitochondrial transmembrane potential in yeast through regulation of $F_{0} F_{1}$-ATPase and a corresponding increase of its ATP-hydrolysing activity (Machida and Tanaka, 1999).

Farnesol is a 15-carbon isoprenoid, a class of compounds naturally produced from mevalonate, which is part of the highly conserved sterol biosynthetic pathway. Components derived from this pathway often act as signalling molecules that affect lipid synthesis, protein synthesis and degradation, developmental patterning, meiosis and apoptosis (reviewed by Edwards and Ericsson, 1999). Farnesol is generated within cells by enzymatic dephosphorylation of farnesyl pyrophosphate (FPP). FPP plays an important role as a precursor of protein prenylation, a post-translation modification of proteins (Edwards and Ericsson, 1999). Known farnesylated proteins include Ras and Ras-related GTP-binding proteins (G proteins), which control cell growth, differentiation, proliferation and survival.

The ability to grow as hyphae is a defining feature of the filamentous fungi (Harris et al., 2005). Typically, hyphae originate from a swollen spore in a process that superficially resembles the yeast-to-mycelium transition of C. albicans. Whether farnesol has a general role in this pivotal stage of hyphal morphogenesis has not yet been determined. Accordingly, to obtain a broader perspective on the role of farnesol in fungal biology, we examined its 
effects on the filamentous fungus Aspergillus nidulans. We report that exposure to farnesol does not block germ tube formation in this fungus. However, farnesol does cause apoptosis in a manner that depends on mitochondrial function, the production of ROS and heterotrimeric $\mathrm{G}$ protein signals. Moreover, our observations suggest that farnesol mediates an unexpected interaction between $C$. albicans and $A$. nidulans. These results reveal a mechanism that may be employed by fungi to antagonize the growth of competitors.

\section{Results}

\section{Farnesol induces nuclear condensation independent of mitosis}

Germinating A. nidulans spores and growing hyphae were exposed to a range of farnesol concentrations (10$250 \mu \mathrm{M}$ ) to determine its effects on hyphal morphogenesis. No obvious effect on the establishment of hyphal polarity was observed. However, at the lowest concentration tested $(10 \mu \mathrm{M})$, farnesol caused a complete inhibition of hyphal growth (Figure 1). Furthermore, to our surprise, we found that extracellular farnesol triggered rapid DNA condensation. Mitosis in A. nidulans is usually completed within 5 min (Bergen and Morris, 1983), such that in an asynchronous population only about $5 \%$ of hyphae possess condensed nuclei (Morris, 1975). However, after treatment with farnesol, a dramatic increase in the number of condensed nuclei was observed (Figure 2A). Notably, the percentage of condensed nuclei increased in a dose-dependent manner, such that $>90 \%$ of nuclei were condensed following treatment with $250 \mu \mathrm{M}$ farnesol for $2 \mathrm{~h}$. These effects are likely the result of farnesol treatment because they were suppressed by the presence

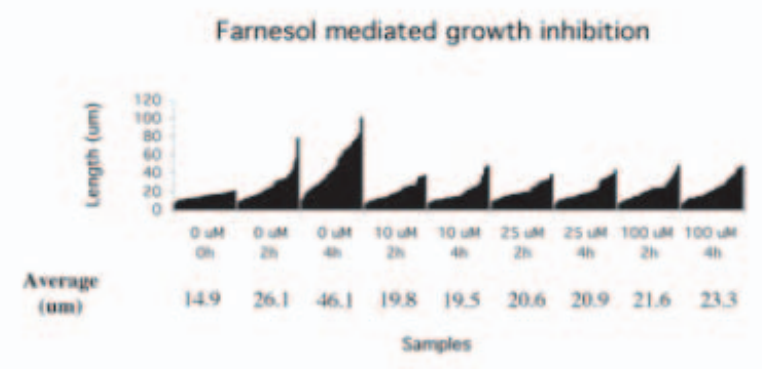

Figure 1. Farnesol inhibits the growth of $A$. nidulans hyphae. Spores of wild-type strain A28 were germinated on coverslips in YGV for $12 \mathrm{~h}$ at $30^{\circ} \mathrm{C}$, followed by treatment for 0,2 or $4 \mathrm{~h}$ with $0,10,25$ and 100 $\mu \mathrm{M}$ farnesol. Nuclei were visualized using Hoechst 33258 and individual images from hyphae containing eight or more nuclei were captured using a Photometrics CoolSnap HQ CCD camera. IP Laboratory software was used to obtain lengths of 40 hyphae, from each sample, which were then plotted using Microsoft Excel. The figure presents the length of all 40 hyphae for each condition (obtained from two independent experiments). The average hyphal length for each sample is indicated at the bottom of the figure. Note that the length distributions for hyphae treated with 1 or $10 \mu \mathrm{M}$ farnesol are identical. of $1 \%$ BSA, which binds lipophilic molecules such as farnesol (Mosel et al., 2005). Note that the growth of the small percentage of hyphae without condensed nuclei was still inhibited, thereby suggesting that they did not represent a farnesol-resistant sub-population.

The observed increase in nuclear condensation could reflect the ability of farnesol to trigger mitotic arrest. If so, nuclear condensation should not be observed if the cell cycle is blocked in interphase by a temperature-sensitive nim mutation ('never in mitosis'; Morris, 1975). To test this hypothesis, a nimT23 ${ }^{c d c 25}$ mutant was used to arrest the cell cycle in $\mathrm{G} 2$ before treatment with farnesol. nimT23 ${ }^{c d c 25}$ encodes the A. nidulans homologue of the fission yeast Cdc25 tyrosine phosphatase that triggers mitotic entry by activating the cyclin-dependent kinase Cdc2 (O'Connell et al., 1992). Both wild-type and nimT23 $3^{c d c 25}$ conidiospores were germinated at $30^{\circ} \mathrm{C}$ for $12 \mathrm{~h}$ and then shifted to restrictive temperature (i.e. $45^{\circ} \mathrm{C}$ ) for $2 \mathrm{~h}$ prior to addition of $100 \mu \mathrm{M}$ farnesol. During continued incubation at $45^{\circ} \mathrm{C}$ (Figs $2 \mathrm{~B}$ and $1 \mathrm{C}$ ), farnesol induced nuclear condensation in both wild-type hyphae (Figure 2B, right panel) and nimT23 ${ }^{c d c 25}$ hyphae arrested in $\mathrm{G} 2$ (Figure 2C, right panel). These results show that nuclear condensation induced by farnesol is independent of mitosis.

\section{Farnesol induces phenotypic changes characteristic of apoptosis}

We tested the hypothesis that farnesol-induced nuclear condensation is a reflection of apoptotic-like programmed cell death in $A$. nidulans. Consistent with this view, hyphae treated with farnesol exhibited increased uptake of the stain Evan's Blue, which is a characteristic feature of dead fungal cells (Wu and Glass, 2001; Figure $\mathrm{S1}$ ). Apoptosis is distinguished by a number of morphological changes that occur during cell death. Features conserved from yeast to mammalian cells include DNA condensation and fragmentation, exposure of phosphatidylserine (PS) on the cell surface and production of ROS (Madeo et al., 1997; 1999; 2004). We initially tested for DNA fragmentation and PS externalization.

The TUNEL assay was used to determine if farnesol induces DNA fragmentation. This assay uses terminal deoxynucleotidyltransferase to label 3'-OH DNA termini with FITC-conjugated dUTP, which can be directly visualized by fluorescence microscopy. After $2 \mathrm{~h}$ treatment with $100 \mu \mathrm{M}$ farnesol, the majority of hyphae $(56 \%)$ showed TUNEL positive staining (Figure $3 \mathrm{~A}$ and $B)$, whereas untreated control hyphae showed no staining.

Mitochondria play a crucial role in apoptosis (Ludovico et al., 2002) by releasing pro-apoptotic factors that contribute to both the caspase-dependent and caspase-independent pathways of apoptosis (reviewed by Kroemer and Martin, 2005 and by Bras et al., 2005). 


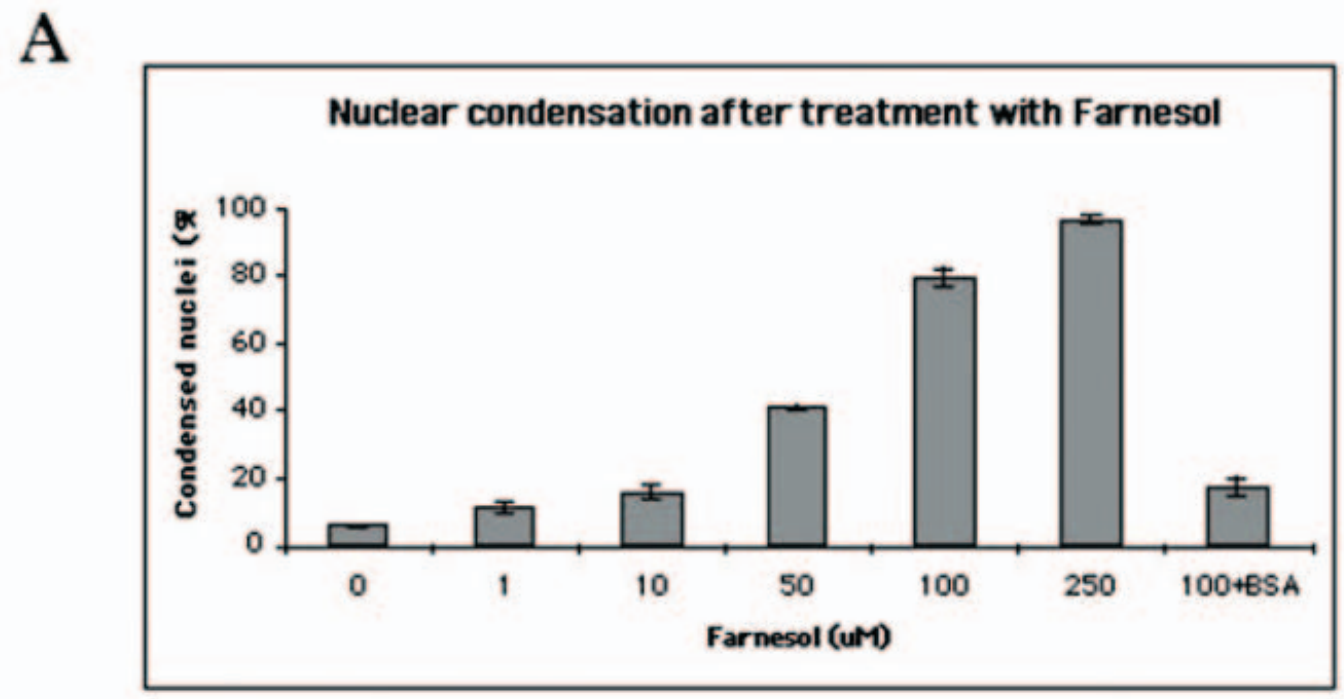

B

No Drug

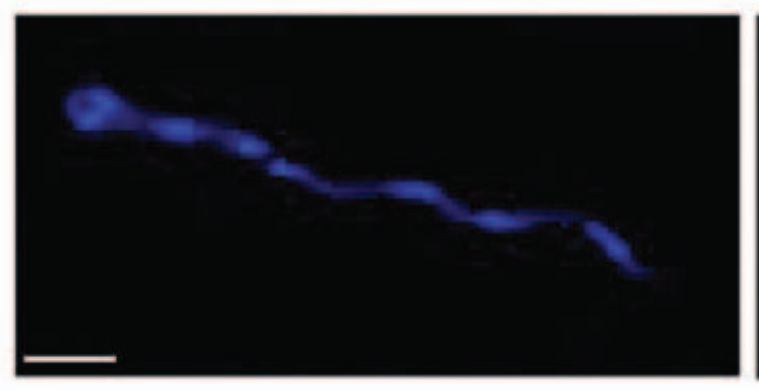

$\mathrm{C}$

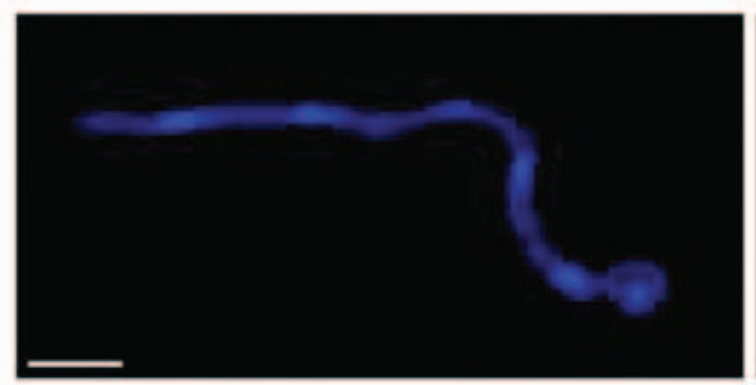

Farnesol
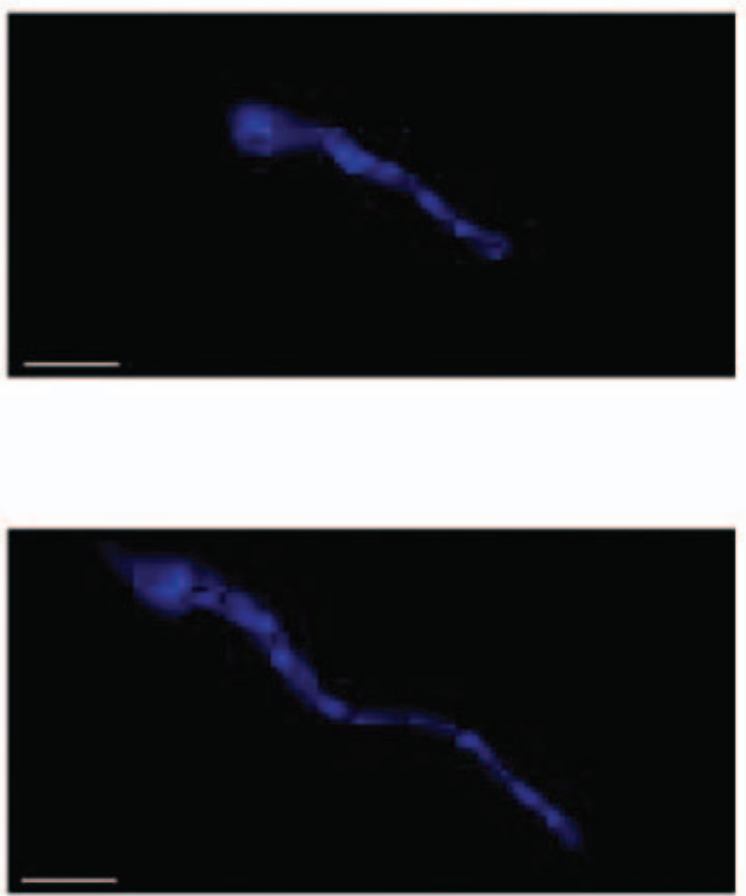

Figure 2. Mitosis-independent nuclear condensation induced by farnesol. (A) Percentage of nuclei showing DNA condensation induced by farnesol. Spores of wild-type strain A28 were germinated on coverslips in YGV for $12 \mathrm{~h}$ at $30^{\circ} \mathrm{C}$, followed by treatment for $2 \mathrm{~h}$ with $0,10,50,100$ or 250 $\mu \mathrm{M}$ farnesol plus a control using $1 \%$ BSA and $100 \mu \mathrm{M}$ farnesol. Nuclei were visualized using Hoechst 33258 and the proportion containing condensed DNA determined. For each sample, 200 nuclei were examined in two independent experiments, with at least two replicates per experiment. Spores of strains A28 (B) and MO73 (C) were germinated on coverslips in YGV medium for $12 \mathrm{~h}$ at $30^{\circ} \mathrm{C}$ and then shifted to $45^{\circ} \mathrm{C}$ for $2 \mathrm{~h}$. One hundred microgram farnesol was added and the strains were incubated at $45^{\circ} \mathrm{C}$ for an additional $2 \mathrm{~h}$. The germinated spores were stained with Hoechst 33258 and analyzed by laser scanning confocal microscopy. The micrographs show a z series stack of $1 \mu \mathrm{m}$ sections. Bars, $10 \mu \mathrm{m}$.

To confirm the role of mitochondria in farnesol-induced apoptosis, we blocked normal mitochondrial function in wild-type hyphae with oligomycin, a specific inhibitor of mitochondrial $F_{0} F_{1}$-ATPase. Pretreatment with oligomycin markedly inhibited nuclear condensation caused by subsequent treatment with farnesol (Figure 3C-E), and hyphae treated with both oligomycin and farnesol were TUNEL negative (Figure $3 \mathrm{C}$ and $\mathrm{D}$ ). Together, these results demonstrate that normal mitochondrial function is essential for farnesol-induced apoptosis. 

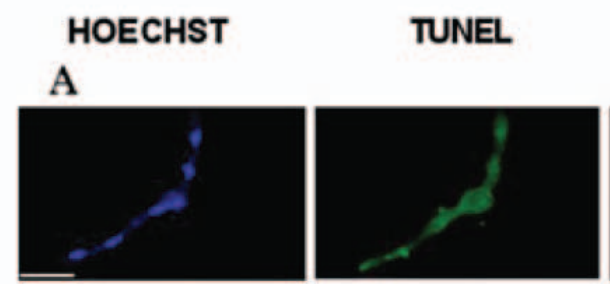

B
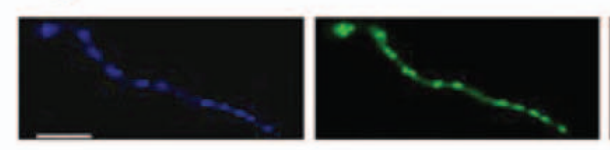

C
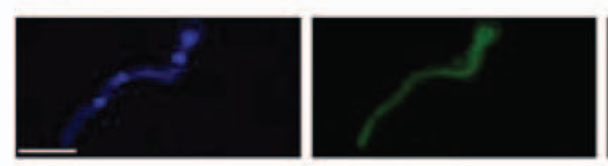

D
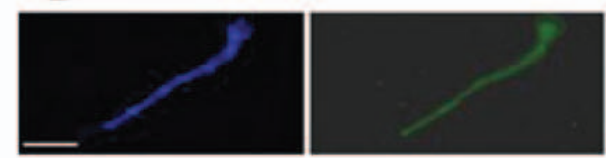
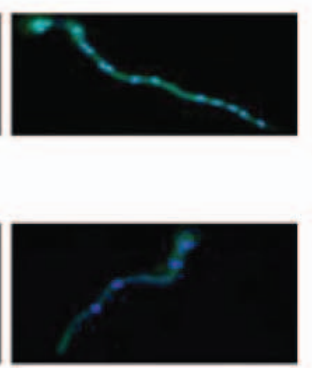

Merged

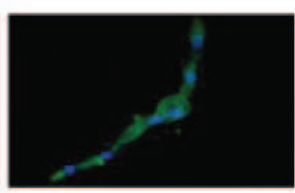

.

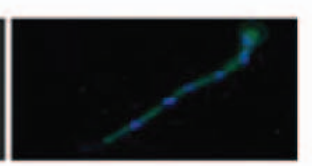

E

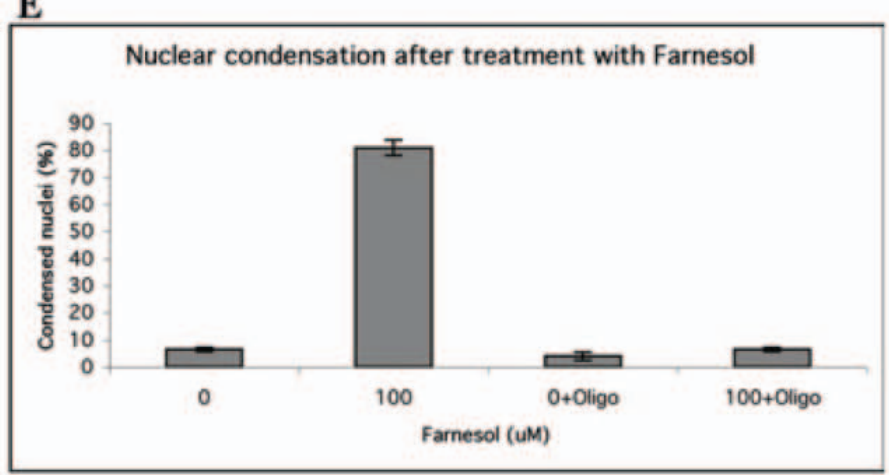

\section{F}

$\mathrm{FOH}$

DIC
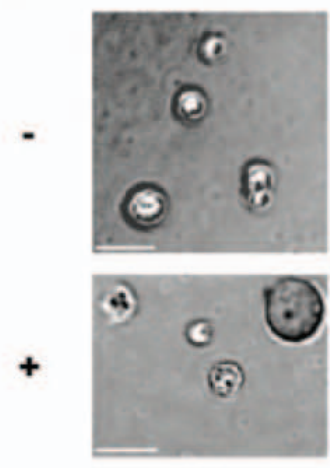

FITC
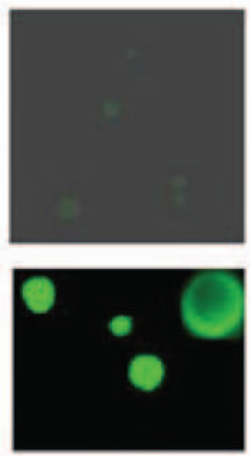

PI
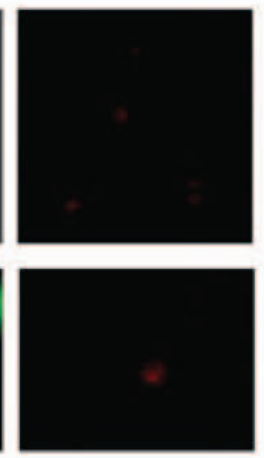

Figure 3. Farnesol-treated hyphae exhibit morphological changes characteristic of apoptosis. A-D. TUNEL assay. Spores of strain A28 were germinated on coverslips in YGV medium for $12 \mathrm{~h}$ at $30^{\circ} \mathrm{C}$. The germinated spores were transferred to YGV containing $0(A)$ or $100 \mu M(B)$ farnesol and incubated at $30^{\circ} \mathrm{C}$ for an additional $2 \mathrm{~h}$. The germinated spores were then fixed and double stained with Hoechst 33258 and TUNEL. The micrographs represent a z series stack of $1 \mu \mathrm{m}$ sections obtained with a laser scanning confocal microscope. Bars, $10 \mu \mathrm{m}$. The same experiment was repeated with hyphae that were pre-grown for $12 \mathrm{~h}$ and then treated with $10 \mu \mathrm{M}$ oligomycin (Sigma, St Louis) for $4 \mathrm{~h}$. Farnesol was added at 0 (C) and $100 \mu \mathrm{M}(\mathrm{D})$, followed by incubation at $30^{\circ} \mathrm{C}$ for an additional $2 \mathrm{~h}$. Micrographs were obtained as described above. E. Percentage of nuclei showing DNA condensation in hyphae treated as described in (A-D). For each sample, 200 nuclei were examined in two independent experiments, with at least two replicates per experiment. F. Annexin $V$ assay. A28 spores were germinated in $Y G V$ medium for $12 \mathrm{~h}$ at $30^{\circ} \mathrm{C}$, then treated with $100 \mu \mathrm{M}$ farnesol and incubated at $30^{\circ} \mathrm{C}$ for an additional $2 \mathrm{~h}$. Protoplasts were generated from each condition and double stained with FITC-Annexin V and PI. One protoplast showing Annexin V positive and PI negative staining was enlarged for observation (upper right corner). The micrographs represent a $z$ series stack of $1 \mu \mathrm{m}$ sections obtained with a laser scanning confocal microscope. Bars, $10 \mu \mathrm{m}$.

We next used the Annexin $\mathrm{V}$ assay to determine if externalization of PS occurs after treatment with farnesol. Normally, PS is only on the inner surface of the cytoplasmic membrane. During apoptosis, plasma membrane asymmetry is lost and PS becomes exposed on the outer leaflet. Annexin $V$ specifically binds to this lipid with high affinity in the presence of $1.8 \mathrm{mM} \mathrm{Ca}^{2+}$. Protoplasts derived from hyphae treated with $100 \mu \mathrm{M}$ farnesol for $2 \mathrm{~h}$ exhibited strong labelling with FITC-conjugated Annexin V (72\%; Figure 3F, lower panels), whereas those derived from untreated control cells did not $(0 \%$; Figure $3 \mathrm{~F}$, upper panels). Propidium iodide (PI) staining showed that the plasma membranes of protoplasts from both treated and control hyphae remained largely intact (Figure 3F, right panels).

Farnesol-induced ROS production is required for apoptosis
A consequence of mitochondrial alterations during apoptosis is disruption of the electron transport chain and subsequent production of ROS (Bras et al., 2005). For example, hydrogen peroxide $\left(\mathrm{H}_{2} \mathrm{O}_{2}\right)$, which is capable of inducing oxidative stress, triggers apoptosis in $S$. cerevisiae (Madeo et al., 1999). To test whether farnesol treatment induces oxidative stress in A. nidulans, we monitored intracellular ROS levels after treatment with farnesol by using 2',7'-dichlorodihydrofluorescein diacetate (DCF). DCF is a cell-permeable ROS indicator that penetrates live cells but does not fluoresce unless oxidized by ROS (LeBel et al., 1992). Protoplasts produced from cells treated with farnesol as well as from untreated controls were assayed with DCF (Chen and Dickman, 2005). As shown in Figure 4A, farnesol-treated cells displayed intense fluorescence (83\%), indicating that ROS is being generated, whereas the untreated controls did not fluoresce $(0 \%)$. 
A
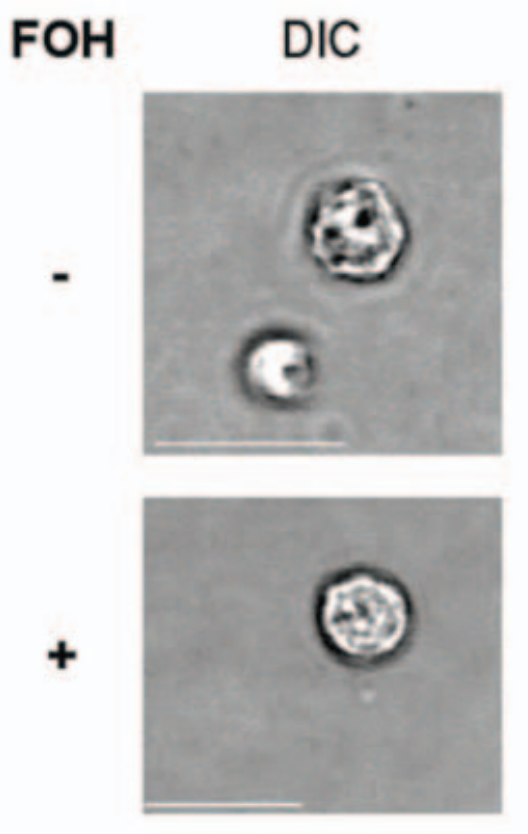

DCF
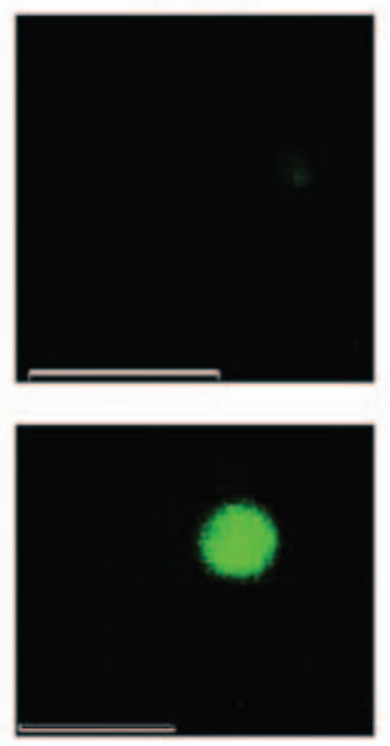

Figure 4. Farnesol induces ROS production and its effects can be reversed by antioxidant. A. A28 spores were germinated in YGV medium for $12 \mathrm{~h}$ at $30^{\circ} \mathrm{C}$ and then treated with 100 $\mu \mathrm{M}$ farnesol and incubated at $30^{\circ} \mathrm{C}$ for an additional $2 \mathrm{~h}$. Protoplasts were generated and incubated with $50 \mu \mathrm{M}$ DCF. The micrographs represent a $z$ series stack of $1 \mu \mathrm{m}$ sections obtained with a laser scanning confocal microscope. Bars, $10 \mu \mathrm{m}$. B. Spores of wildtype strain $\mathrm{A} 28$ were germinated in $\mathrm{MN}$ for 12 $h$ at $30^{\circ} \mathrm{C}$ in the absence of antioxidant (control), or in the presence of either $5 \mathrm{mM} \mathrm{L-pro-}$ line or $5 \mathrm{mM}$ NAC. Germlings were then treated with $1 \mathrm{mM} \mathrm{H} 2 \mathrm{O} 2$ or $100 \mu \mathrm{M}$ farnesol and incubated at $30^{\circ} \mathrm{C}$ for an additional $2 \mathrm{~h}$. The germinated spores were fixed and stained with Hoechst 33258 and the percentage of nuclei showing DNA condensation was determined by fluorescence microscopy. For each sample, 200 nuclei were examined in two independent experiments, with at least two replicates per experiment.

B

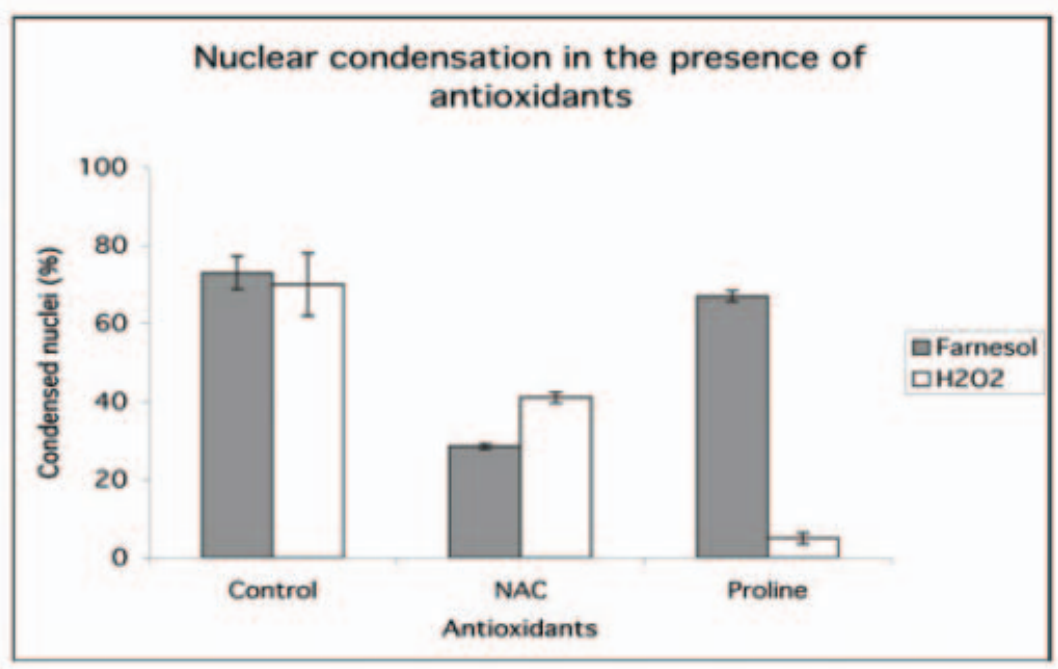

To determine if ROS production participates in farnesol-induced apoptosis, we tested the possibility that scavenging of ROS may suppress the effects of farnesol. As ROS scavengers we used the antioxidants $\mathrm{N}$ acetyl cysteine (NAC) and I-proline. I-proline is known to suppress $\mathrm{H}_{2} \mathrm{O}_{2}$-induced apoptosis in the fungus $\mathrm{Col}$ letotricum trifolli (Chen and Dickman, 2005). Because it was not clear that I-proline would behave the same way in $A$. nidulans, we also used $\mathrm{H}_{2} \mathrm{O}_{2}$ as a control to induce ROS formation in $A$. nidulans. Wild-type hyphae were germinated on coverslips for $12 \mathrm{~h}$ in standard minimum media (MN) in the presence of either $5 \mathrm{mM} \mathrm{NAC}$ or $5 \mathrm{mM}$ I-proline and then treated with farnesol or $\mathrm{H}_{2} \mathrm{O}_{2}$ for $2 \mathrm{~h}$. As shown in Figure 4B, NAC partially rescued chromosome condensation in both treatments, where- as I-proline prevented condensation only in cells treated with $\mathrm{H}_{2} \mathrm{O}_{2}$.

Heterotrimeric $G$ protein signals are required for farnesol-induced apoptosis

The antifungal protein PAF triggers apoptosis in A. nidulans via a mechanism that requires the $G \beta$ protein $S f a D$ (Leiter et al., 2005). To determine if PAF and farnesol could act by the same mechanism, we examined the effects of $\triangle s f a D$ and $\triangle f l b A$ mutations on farnesol-induced nuclear condensation. The $\Delta s f a D$ mutation, which blocks $G$ protein signalling (Rosen et al., 1999), conferred complete resistance to farnesol (Table 1). By contrast, the $\triangle f l b A$ mutation, which leads to hyperactivation of the 
Table 1. Farnesol-induced nuclear condensation depends on heterotrimeric $G$ protein signals.

\begin{tabular}{lcl}
\hline Strain/farnesol dose & Nuclei condensation (\%) & SD \\
\hline A28 (wild-type) $/ 0 \mu \mathrm{M}$ & 7.5 & 2.12132034 \\
A28/10 $\mu \mathrm{M}$ & 20.5 & 3.53553391 \\
A28/100 $\mu \mathrm{M}$ & 70.5 & 6.36396103 \\
tSRB $1.21(\Delta \mathrm{SfaD}) / 0 \mu \mathrm{M}$ & 6.5 & 2.12132034 \\
tSRB $1.21 / 10 \mu \mathrm{M}$ & 7.0 & 1.41421356 \\
tSRB $1.21 / 100 \mu \mathrm{M}$ & 8.0 & 1.41421356 \\
rJA5.9 $(\Delta f \mathrm{flbA}) / 0 \mu \mathrm{M}$ & 15.5 & 0.70710678 \\
rJA5.9/10 $\mu \mathrm{M}$ & 78.0 & 2.82842712 \\
rJA5.9/100 $\mu \mathrm{M}$ & 95.5 & 0.70710678 \\
\hline
\end{tabular}

Spores from strains A28, tSRB 1.21 and rJA5.9 were germinated on coverslips in $\mathrm{YGV}$ for $12 \mathrm{~h}$ at $30^{\circ} \mathrm{C}$, followed by treatment for $2 \mathrm{~h}$ with 0,10 and $100 \mu \mathrm{M}$ farnesol. Nuclei were visualized using Hoechst 33258 and the proportion containing condensed DNA determined. For each sample, 200 nuclei were examined, and the results represent the average of two independent experiments, with two replicates per experiment.

Ga protein FadA (Yu et al., 1996), caused a dramatic increase in sensitivity to farnesol (Table 1). Notably, the level of nuclear condensation observed in $\triangle \mathrm{flbA}$ mutants treated with $10 \mu \mathrm{M}$ farnesol is equivalent to that seen in wild-type hyphae at a concentration of $100 \mu \mathrm{M}$. These observations suggest that the FadA G protein complex is part of the signal transduction pathway that promotes apoptosis in hyphae exposed to farnesol.

\section{Candida albicans and farnesol inhibit growth and devel- opment of $A$. nidulans}

To address the possibility that $A$. nidulans secretes farnesol, wild-type hyphae were grown in liquid media, the culture was pelleted, and the cell free supernatant was analysed for farnesol by gas chromatography/ mass spectroscopy (GC/MS). Commercial mixed isomer farnesol was used as a control. With a detection limit of $0.005 \mathrm{mg} \mathrm{g}^{-1}$, farnesol was not found in the spent media (Figure S2). Because farnesol is apparently not secreted in detectable quantities by $A$. nidulans under the conditions tested, this fungus is presumably responding to farnesol produced by other fungal species.

The possibility that farnesol from $C$. albicans might affect $A$. nidulans was evaluated in co-culture. Wildtype strains of both fungi were grown in defined glucose, proline and phosphate media (GPP) with added nitrate salts at $30^{\circ} \mathrm{C}$ for $24 \mathrm{~h}$. As controls, C. albicans and $A$. nidulans were grown by themselves, and they were also co-cultured in the presence of $1 \%$ BSA, which displays non-specific binding to lipids such as farnesol (Mosel et al., 2005). Following growth, the cultures were washed, plated onto YPD media, and incubated at $30^{\circ} \mathrm{C}$ for 2 days. Pure cultures were recovered when $C$. albicans and $A$. nidulans were grown separately (Figure $5 \mathrm{~A}$ and $\mathrm{B}$ ) but only $\mathrm{C}$. albicans was recovered when both fungi had been grown together (Figure 5C). Significantly, this effect was reversed by the addition of BSA (Figure 5D). Macroscopic characteristics of the colonies were used to distinguish the two fungi: $C$. albicans colonies were mucoid whereas $A$. nidulans colonies were hyaline and downy in texture (note that $A$. nidulans sporulates poorly in YPD media). Less than $10^{3} A$. nidulans cfu were recovered when co-cultured with $C$. albicans, an inhibition of $\geq 180 \times$. Moreover, in separate experiments, spent media from C. albicans A72 cultures blocked A. nidulans colony formation in a dose-dependent manner (Figure S3). These observations demonstrate that C. albicans produces a lipophilic compound capable of inhibiting the growth of $A$. nidulans. To confirm that this compound was farnesol, we analysed the supernatants of all four cultures by GC/MS. As expected, the C. albicans culture supernatant presented a peak at $11.25 \mathrm{~min}$ whose MS peak analysis gave a perfect match (95 degree of similarity) whereas the $A$. nidulans supernatant presented no peak with any similarity to farnesol (data not shown). Peak area for the $C$. albicans supernatant indicated a farnesol concentration of $0.66 \mu \mathrm{M}$. Farnesol was also detected in the $C$. albicans and $A$. nidulans co-culture supernatant $(0.58 \mu \mathrm{M})$ and in a lower concentration in the co-culture with BSA $(0.017 \mu \mathrm{M})$ (data not shown). These concentrations of farnesol (0.58$0.66 \mu \mathrm{M})$ are just below that normally found when $C$. albicans is grown in GPP media $(2-4 \mu \mathrm{M})$, and are within range of concentrations of commercial farnesol that completely inhibit hyphal growth $(1-10 \mu \mathrm{M}$; Figure 1and data not shown). Collectively, these results suggest that co-cultivation with $C$. albicans can inhibit the growth of $A$. nidulans in a farnesol-dependent manner.

We also tested $A$. nidulans hyphae for the appearance of nuclear condensation when grown in the presence of $C$. albicans. The fungi were grown separately for $12 \mathrm{~h}$ and then added together such that $A$. nidulans was exposed to increasing amounts of the $C$. albicans culture. The co-culture was incubated at $30^{\circ} \mathrm{C}$ for an additional $2 \mathrm{~h}$ and nuclear condensation was measured by microscopy. As expected, the percentage of condensed nuclei increased as a function of $C$. albicans cell density (Figure $5 \mathrm{E}$ ).

We then inoculated $A$. nidulans on solid media with or without $C$. albicans. As shown in Figure 5F, the presence of $C$. albicans limited the growth of $A$. nidulans and prevented the development of conidiophores. Note that $A$. nidulans did not grow over the $C$. albicans streak line, but could expand in the opposite direction. By contrast, when paired with $S$. cerevisiae (strain BY4741), A. nidulans could grow over the streak line (data not shown), thereby suggesting that the inability to grow over $C$. albicans reflects an antagonistic interaction between these fungi. To determine how farnesol travelled from $C$. albicansTo $A$. nidulans, a series 


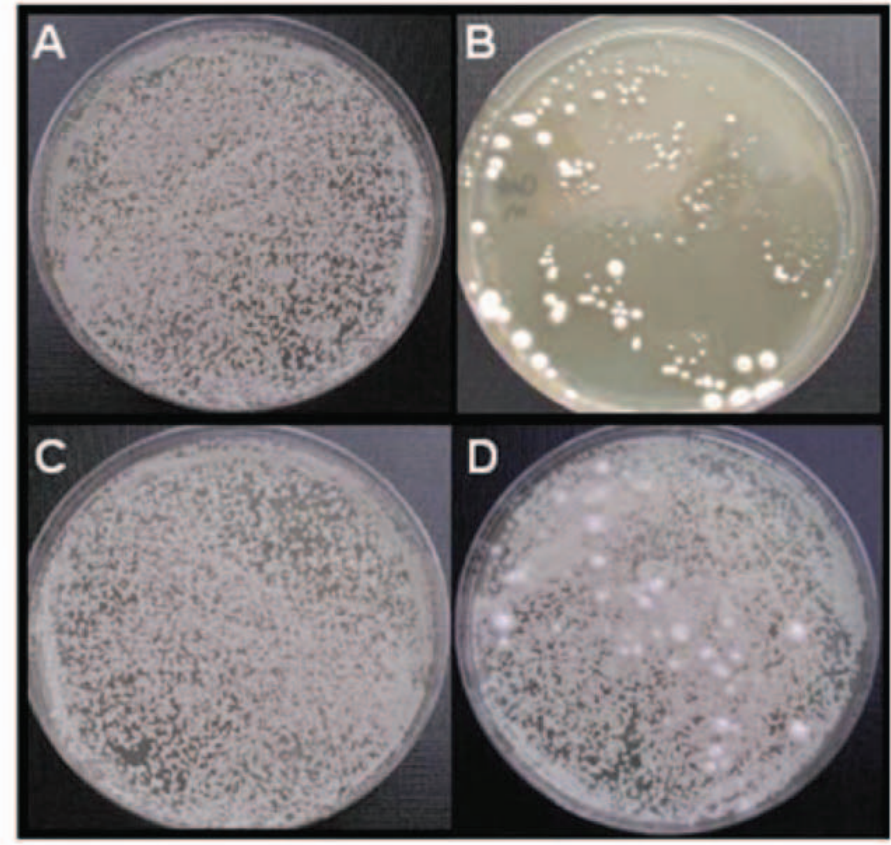

E

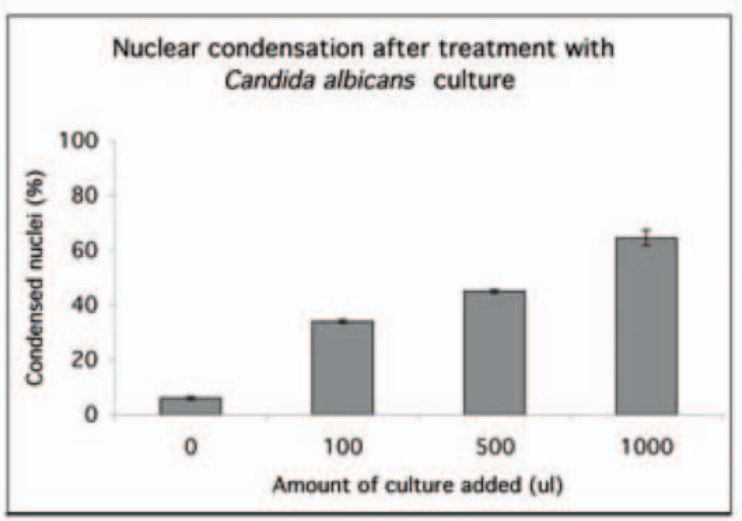

F

$\mathbf{F}$

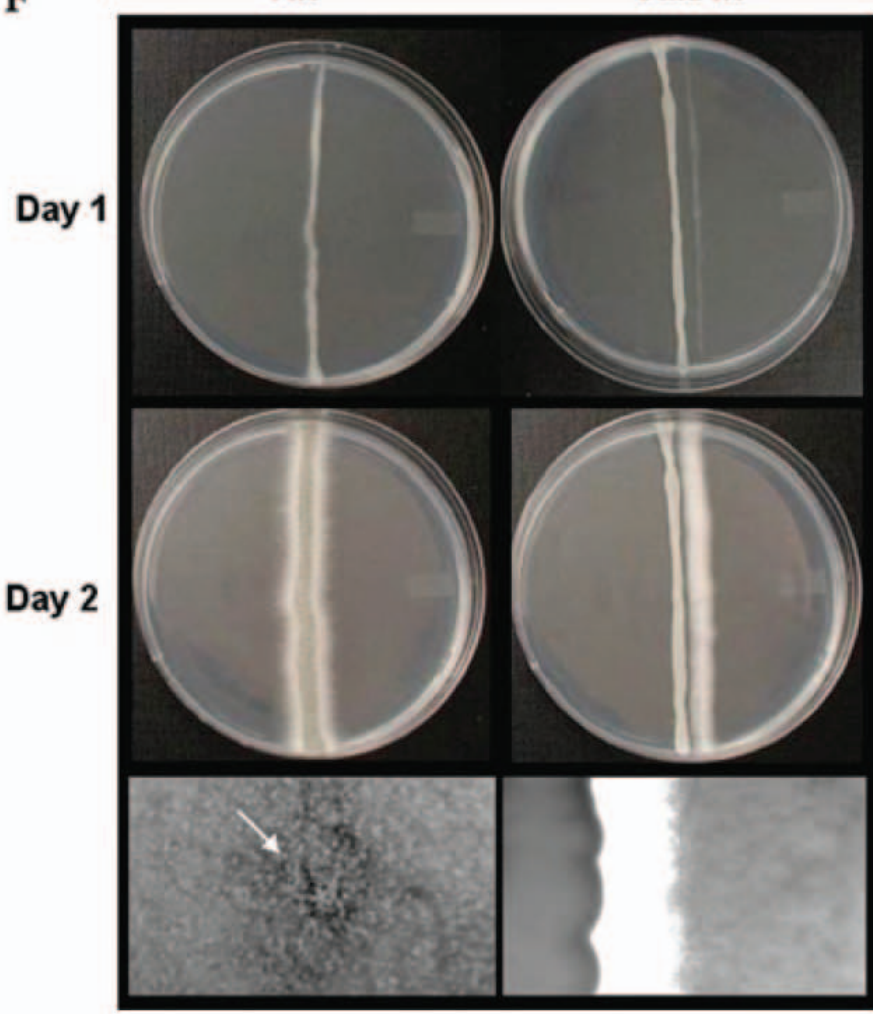

G

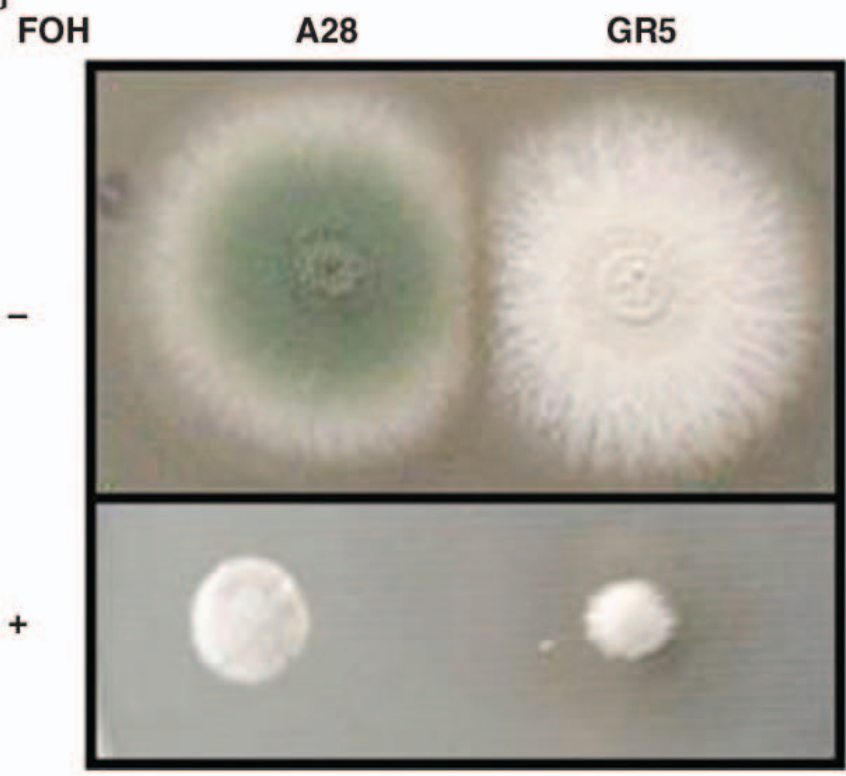

Figure 5. Candida albicans and farnesol inhibit growth and development of A. nidulans. A-D. Strains of (A) C. albicans (A72) (B) A. nidulans (A28) (C) C. albicans and A. nidulans and (D) C. albicans and A. nidulans plus $1 \%$ BSA were grown in GPP at $30^{\circ} \mathrm{C}, 200 \mathrm{rpm}$ for $24 \mathrm{~h}$. The cultures were washed, diluted and plated onto YPD and incubated at $30^{\circ} \mathrm{C}$ for 2 days.

E. A. nidulans strain A28 was grown in YGV media for $12 \mathrm{~h}$ at $30^{\circ} \mathrm{C}$, then treated with the indicated amounts of C. albicans (strain A72) culture grown separately in GPP for $12 \mathrm{~h}$. The co-culture (final volume $10 \mathrm{ml}$ ) was incubated at $30^{\circ} \mathrm{C}$ for an additional $2 \mathrm{~h}$ and treated as described above.

F. A. nidulans strain A28 was inoculated in solid YGV media by itself (left panels) or in the presence of C. albicans strain A72 (right panels), and incubated at $30^{\circ} \mathrm{C}$ for 1 (upper panels) or 2 days (middle panels). Note that $A$. nidulans only forms conidia when grown alone. It displays an aconidial phenotype in the presence of $C$. albicans. To better illustrate this phenotype, higher magnification (10x) images obtained with a dissecting microscope are displayed in the lower panels. Arrow indicates conidiophores.

G. A. nidulans strains A28 (left) and GR5 (right) were inoculated in CMUU that was left untreated or also contained $500 \mu \mathrm{M}$ farnesol. Plates were sealed with parafilm to limit farnesol evaporation, and incubated at $30^{\circ} \mathrm{C}$ for 3 days. 
of experiments was done in sealed centre well flasks. Whenever $C$. albicans or farnesol was put in the centre well, A. nidulans in the separated outer portion of the flask showed the same developmental phenotype, i.e. no conidiophores (data not shown). This result indicates that farnesol not only diffuses through the media but is also volatile.

Finally, we tested the effect of farnesol on A. nidulans growth in solid media. Two A. nidulans strains, A28 (green-spored) and GR5 (white-spored), were inoculated onto standard complete media agar plates containing $100-500 \mu \mathrm{M}$ of farnesol. The plates were sealed to limit farnesol evaporation and incubated at $30^{\circ} \mathrm{C}$ for 2 days. To our surprise, only the higher farnesol concentration (i.e. $500 \mu \mathrm{M}$ ) was capable of inhibiting A. nidulans growth and conidiation (Figure $5 \mathrm{G}$ ), while lower concentrations of farnesol simply inhibited conidiophore formation (data not shown). The fact that a higher concentration of farnesol was necessary to inhibit $A$. nidulans growth in solid media can be explained by the difference in incubation time. Because the plates were incubated for an extended period ( 3 days, compared with $2 \mathrm{~h}$ of incubation in liquid media), it is possible that prolonged exposure of farnesol to oxygen may lead to loss of its activity.

\section{Discussion}

We have demonstrated that the isoprenoid farnesol induces apoptosis in the filamentous fungus $A$. nidulans via a mechanism that requires functional mitochondria, the production of ROS and a heterotrimeric $G$ protein complex. In addition, we have also shown that $C$. albicans inhibits the growth and development of $A$. nidulans in a manner that is likely farnesol-dependent. Our results reveal a possible mechanism that may underlie antagonistic interactions between fungi within microbial communities.

\section{Induction of apoptosis by farnesol}

Apoptotic-like programmed cell death has been observed in a number of filamentous fungi, and farnesol joins a growing list of compounds $\left(\mathrm{H}_{2} \mathrm{O}_{2}\right.$, amphotericin $\mathrm{B}$, the antifungal protein $\mathrm{PAF}$, sphingoid bases) that trigger this response (Cheng et al., 2003; Mousavi and Robson, 2004; Chen and Dickman, 2005; Leiter et al., 2005). Characteristic features of apoptosis in filamentous fungi include a requirement for functional mitochondria and, in most cases, ROS production, as well as the absence of dependency on caspase activity. Although the nature of the signalling and effector pathways that regulate fungal apoptosis remain under investigation (Madeo et al., 2004), preliminary insights have been obtained. For example, dominant active Ras promotes apoptosis in C. trifolii (Chen and Dickman, 2005). Our observations, and those of Leiter et al. (2005), also implicate the heterotrimeric $\mathrm{Ga}$ protein FadA in promoting apoptosis in A. nidulans. Whether Ras and $\mathrm{Ga}$ act together in a linear pathway, or via parallel mechanisms, to cause apoptosis is an intriguing issue that merits further investigation. Finally, our recent results also suggest that poly (ADP-ribose) polymerase (PARP) function is required for farnesol-induced apoptosis (C.P. Semighini et al., unpubl. obs.).

The ability of farnesol to cause apoptosis is not limited to fungal cells. Farnesol-induced apoptosis has been reported in tobacco cells (Hemmerlin and Bach, 2000) and several tumour-derived cell lines (Adany et al., 1994; Haug et al., 1994; Voziyan et al., 1995; Rioja et al., 2000). Farnesol is also capable of arresting the growth of animal cells and S. cerevisiae (Chakrabarti and Engleman, 1991; Burke et al., 1997; Machida et al., 1998; 1999). In both yeast and $A$. nidulans, farnesol treatment induces intracellular ROS generation (Machida et al., 1998; 1999). Furthermore, in both cases, the antioxidant NAC can ameliorate the effects induced by farnesol. These results indicate that ROS production is an important factor underlying farnesol-induced apoptosis. However, unlike NAC, I-proline could not reverse the effects of farnesol, though as expected (Chen and Dickman, 2005), it did prevent nuclear condensation in hyphae exposed to $\mathrm{H}_{2} \mathrm{O}_{2}$. One explanation for this difference is that farnesol may generate a specific intracellular ROS that can only be neutralized by NAC. In this context, it should also be noted that strain GR5 (whitespored) is significantly more sensitive than A28 (greenspored) to farnesol in solid media. The difference between A28 and GR5 may reflect the fact that pigmented strains are more resistant to ROS stress (Langfelder et al., 2003). For example, in Aspergillus fumigatus, melanin was implicated in both cAMP signalling and ROS detoxification (Liebmann et al., 2003).

Antagonistic interactions between fungi and the possible roles of farnesol

Our results show that an antagonistic relationship exists between C. albicans and A. nidulans. This effect is not unique to $A$. nidulans, as we have recently observed that $C$. albicans $\mathrm{A} 72$ also blocks the growth and development of other euascomycete fungi, including $A$. fumigatus and Fusarium graminearum. Moreover, as with $A$. nidulans, the response of these two fungi to the presence of $C$. albicans can be mimicked by extracellular farnesol (C.P. Semighini et al., unpubl. obs.). Finally, extracellular farnesol also triggers apoptosis in $A$. fumigatus and F. graminearum (C.P. Semighini et al., unpubl. obs.). Taken together, our observations suggest that the response to farnesol may account in part for the antagonistic interactions between $C$. albicans and euascomycetes. Moreover, this response appears to be graded. In particular, lower concentrations of farne- 
sol, whether produced by $C$. albicans $(0.5-4 \mu \mathrm{M}$; Hornby et al., 2001; 2003) or applied externally $(1-10 \mu \mathrm{M})$, inhibit hyphal growth and colony development. At higher concentrations (50-100 $\mu \mathrm{M})$, which do not affect the viability or growth of C. albicans (Hornby et al., 2001), farnesol causes nuclear condensation and cell death. However, it should be emphasized that low but reproducible levels of nuclear condensation could be triggered by farnesol even at a concentration as low as $10 \mu \mathrm{M}$ (Figure 2A).

Antagonistic interactions between fungi have been well documented in the past. For instance, Waksman (1941) cited at least 13 examples of antagonistic effects of one fungus on another. Notably, the dermatophyte Trichophyton rubrum failed to grow when co-cultivated with either $C$. albicans or spent culture media that had been filtered, indicating that the latter secretes a metabolic product with fungistatic action (Jillson and Nickerson, 1948). Our observations suggest that the metabolic product could be farnesol. Whether farnesolbased antagonisms occur in a natural setting remains uncertain. One possibility is that $C$. albicans may use farnesol to eliminate other fungal competitors within the mammalian host environment. This notion is supported by the observation that pure cultures of $C$. albicans are generally isolated from lesions, implying that C. albicans exerts an inhibitory effect on the growth of other microbes (Lewis and Hooper, 1943). Alternatively, isolates of $C$. albicans have been recovered from soil samples from New Zealand (di Menna, 1955) and Tennessee (Ajello, 1956), though it is not known if they exist passively following introduction by animal carriers or if they are normal components of soil communities. If $C$. albicans in fact inhabits the soil, it is possible that this fungus secretes farnesol to kill other fungi sharing the same habitat, such as euascomycetes, in order to reduce competition for nutrient sources. A final consideration is that farnesol may be expressed within the host environment to kill immune cells such as macrophages. Many microbes produce virulence factors that induce apoptosis in host cells (reviewed by MendesGiannini et al., 2000; Moss et al., 2005). For example, a 3-oxo-C12 homoserine lactone quorum-sensing molecule from Pseudomonas aeruginosa was reported to trigger apoptosis in bone marrow-derived macrophages, as well as in neutrophils and monocytic cell lines (Tateda et al., 2003). The significance of this report is that 3-oxo-C12 homoserine lactone has recently been shown (Hogan et al., 2004) to have enough structural similarity to farnesol that at high concentrations $(200 \mu \mathrm{M})$ it can mimic the action of farnesol in C. albicans.

We conclude that farnesol, in addition to its quorumsensing function that regulates morphogenesis, is also employed by $C$. albicansTo reduce competition from oth- er microbes. On a more speculative note, farnesol may be used as a virulence factor to induce apoptosis in host cells. In either case, we propose that farnesol significantly enhances the ability of $C$. albicansTo colonize new environments. Future experiments will determine how C. albicans and filamentous fungi sense farnesol and respond to its presence.

\section{Experimental procedures}

Strains, media and reagents

Aspergillus nidulans strains used were A28 (pabaA6 biA1; Fungal Genetics Stock Center, University of Kansas Medical Center, Lawrence, KS), MO73 (nimT23 pabaA6; Steve Osmani, Ohio State University, Columbus, OH), GR5 (pyrG89; pyroA4; wA3, FGSC), tSRB1.21 ( $\triangle s f a D:: a r g B$; $\operatorname{argB2}$; Jaeyuk Hu, University of Wisconsin-Madison) and rJA5.9 ( $\triangle \mathrm{f} / \mathrm{b} A:$ :argB; $\operatorname{argB2}$; pyrG89; pyroA; Jaeyuk Hu, University of Wisconsin-Madison). The C. albicans strain used was A72 (Patrick Sullivan, University of Otago, Dunedin, New Zealand; also ATCC MYA2430). The following media were used: YGV (2\% glucose, $0.5 \%$ yeast extract, $0.01 \%$ vitamins, trace elements), MN ( $1 \%$ glucose, nitrate salts, trace elements, $\mathrm{pH} 6.5)$, GPP (2\% glucose, $52 \mathrm{mM}$ phosphate and $10 \mathrm{mM}$ proline), YPD (1\% yeast extract, $2 \%$ peptone, $2 \%$ dextrose, $2 \%$ agar) and CMUU $(1 \%$ glucose, $0.1 \%$ yeast extract, $0.2 \%$ peptone, $0.1 \%$ casamino acids, nitrate salts, trace elements, $0.01 \%$ vitamins, $5 \mathrm{mM}$ uridine and $10 \mathrm{mM}$ uracil, $\mathrm{pH}$ 6.5). Trace elements, vitamins and nitrate salts were used as described by Kafer (1977). Transtrans farnesol, BSA, oligomycin, I-proline, NAC or $\mathrm{H}_{2} \mathrm{O}_{2}$ were added to media at the indicated concentration. All chemicals were purchased from Sigma (St. Louis). A $1 \mathrm{M}$ stock solution of farnesol was prepared fresh in DMSO prior to each experiment. The appropriate amount of farnesol was transferred with a pipette from the stock solution to the growth medium. The original flask containing farnesol was de-gassed with nitrogen gas every time after being opened in order to avoid degradation by oxygen.

\section{Measurement of hyphal growth}

A28 spores were germinated on coverslips in YGV medium at $30^{\circ} \mathrm{C}$ for $12 \mathrm{~h}$. The coverslips were treated with 10,25 and $100 \mu \mathrm{M}$ farnesol, and incubated at $30^{\circ} \mathrm{C}$ for 0,2 or $4 \mathrm{~h}$ as indicated. The coverslips were fixed and stained with Hoechst 33258. Slides were viewed using an Olympus BX51 fluorescent microscope and individual images from hyphae containing eight or more nuclei were captured with a Photometrics CoolSnap HQ CCD camera. The length of 40 hyphae for each sample was measured using IPLab software (Scanalytics, Rockville) and plotted with Microsoft Excel.

\section{Chromatin staining}

After $12 \mathrm{~h}$ of germination on coverslips in $\mathrm{YGV}$ medium at $30^{\circ} \mathrm{C}$, strains were treated for $2 \mathrm{~h}$ as indicated. The coverslips were fixed and stained with Hoechst 33258 (Molecular Probes, Oregon) as described by Harris et al. (1994). Slides were viewed using an Olympus BX51 fluorescent microscope and the proportion of nuclei with condensed DNA determined. 


\section{TUNEL assay}

Spores of strain A28 were germinated on coverslips in YGV medium for $12 \mathrm{~h}$ at $30^{\circ} \mathrm{C}$. The germinated spores were treated for $2 \mathrm{~h}$ as indicated, fixed and double stained with Hoechst 33258 and TUNEL (In Situ Cell Death Detection Kit, Roche Diagnostics, Germany) as described by Madeo et al. (1997) and Chen and Dickman (2005). Confocal images were obtained with an Olympus FW500/BX61 confocal laser scanning microscope using the following laserlines: $405 \mathrm{~nm}$ for Hoechst 33258 and $488 \mathrm{~nm}$ for FITC. Images were captured by direct acquisition with a $Z$ step of $1-2 \mu \mathrm{m}$ and were subsequently processed using ImageJ and Adobe PhotoShop 6.0.

\section{Annexin $V$ staining}

A28 spores were germinated in $\mathrm{YGV}$ medium for $12 \mathrm{~h}$ at $30^{\circ} \mathrm{C}$, then treated with $100 \mu \mathrm{M}$ farnesol and incubated at $30^{\circ} \mathrm{C}$ for an additional $2 \mathrm{~h}$. Protoplasts were generated from each condition as described by Oakley and Osmani (1993) and double stained with FITC-Annexin $\mathrm{V}$ and propidium iodine (PI) using the Annexin V-FITC Apoptosis Detection kit (Oncogene Research Products, Boston) as described by Madeo et al. (1997) and Chen and Dickman (2005). Images were obtained by confocal microscopy as described above.

\section{Reactive oxygen species detection}

Intracellular ROS levels in A. nidulans were monitored with the oxidant-sensitive probe 2',7'-dichlorofluorescin diacetate DCF (Molecular Probes, Oregon) as described by Madeo et al. (1997) and Chen and Dickman (2005).

\section{Farnesol detection}

Liquid cultures in GPP media were performed at $30^{\circ} \mathrm{C}$ and $200 \mathrm{rpm}$ for $24 \mathrm{~h}$. Cells were harvested by centrifugation at $4000 \mathrm{~g}$ for $10 \mathrm{~min}$ and the pellet was discarded. The supernatant was sterilized by filtration through a polyethersulfone $0.45 \mu \mathrm{m}$ membrane (Nalgene, Rochester). Cell-free supernatants were extracted in 1/5 volume ethyl acetate (Sigma, St. Louis), which was collected and removed by rotary evaporation. The residue was resuspended in $1 \mathrm{ml}$ ethyl acetate/hexane (1:4) (Sigma, St. Louis) and transferred to a vial to remove particulate material. The solvent was removed by rotary evaporation and the residue was resuspended in $25 \mu$ ethyl acetate/hexane (1:4). One microlitre was analysed by GC/MS. A Shimadzu GC-17A/MS QP5050A was used for chemical analysis in electron ionization (EI) mode using associated software program GCMS Real Time Analysis ver 1.2. The GC column used an initial temperature of $100^{\circ} \mathrm{C}$, held at temperature for $3 \mathrm{~min}$, and then ramped to $300^{\circ} \mathrm{C}$ over $13 \mathrm{~min}$, with a $1 \mathrm{~min}$ hold at $300^{\circ} \mathrm{C}$. Helium, at a flow rate of $1 \mathrm{ml} \mathrm{min}^{-1}$, was used as the carrier gas.

\section{Co-culture assay}

Strains A72 of $C$. albicans and A28 of $A$. nidulans were grown separately or in co-culture in GPP media plus $0.01 \%$ vitamins and nitrate salts at $30^{\circ} \mathrm{C}, 200 \mathrm{rpm}$ for $24 \mathrm{~h}$ (initial inoculum of
$10^{2}$ cells). The cultures were washed, diluted and plated onto YPD and incubated at $30^{\circ} \mathrm{C}$ for 2 days.

\section{Evan's Blue staining}

A28 spores were germinated on coverslips in YGV medium at $30^{\circ} \mathrm{C}$ for $12 \mathrm{~h}$. The coverslips were treated with $100 \mu \mathrm{M}$ farnesol or left untreated. After $2 \mathrm{~h}$ of incubation at $30^{\circ} \mathrm{C}$, the coverslips were flooded with $1 \%$ Evans blue (Sigma, St. Louis) in PBS for $5 \mathrm{~min}$ at room temperature, then washed three times with PBS. Both farnesol-treated and untreated hyphae were examined under bright-field illumination with an Olympus BX51 fluorescent microscope.

\section{Conditioned media assay}

Candida albicans A72 was grown in GPP media for $16 \mathrm{~h}$ at $30^{\circ} \mathrm{C}$ and $200 \mathrm{rpm}$. Cells were harvested by centrifugation at $4000 \mathrm{~g}$ for $10 \mathrm{~min}$ and the pellet was discarded. The supernatant was filter sterilized and an aliquot was autoclaved $\left(121^{\circ} \mathrm{C}\right.$ for $20 \mathrm{~min}$ ) to volatilize the farnesol. The two sets of conditioned media were added to fresh GPP media (plus $0.01 \%$ vitamins and nitrate salts) to give final concentrations of $0,1: 10$ and 1:1 ( $\mathrm{v} / \mathrm{v}$ ratio). A. nidulans A28 strain was inoculated into the media and grown at $30^{\circ} \mathrm{C}, 200 \mathrm{rpm}$ for $24 \mathrm{~h}$. The cultures were washed, diluted and plated onto solid YGV and incubated at $30^{\circ} \mathrm{C}$ for 3 days.

\section{Acknowledgements}

We thank Changbin Chen and Marty B. Dickman for their assistance with TUNEL, Annexin $\mathrm{V}$ and ROS production assays and valuable discussions. We also thank Dhammika Navarathna for his help with chromatography analyses and members of the UNL Microscopy Core Facility for their assistance with the use of the laser scanning confocal microscope. This work was supported by grants from the INBRE Program of the National Center for Research Resources (NIH Grant \# P20 RR016454 to $\mathrm{JMH}$ ), the National Science Foundation (MCB-0110999 to KWN), the University of Nebraska Tobacco Settlement Biomedical Research Enhancement Fund (KWN) and the Nebraska Research Foundation (SDH).

\section{References}

Adany, I., Yazlovitskaya, E.M., Haug, J.S., Voziyan, P.A., Melnykovych, G. ( 1994) Differences in sensitivity to farnesol toxicity between neoplastically- and non-neoplastically-derived cells in culture. Cancer Lett 79: 175- 179.

Ajello, L. ( 1956) Soil as natural reservoir for human pathogenic fungi. Science 123: 876-879.

Bergen, L.G., Morris, N.R. ( 1983) Kinetics of the nuclear division cycle of Aspergillus nidulans. J Bacteriol 156: 155160.

Bras, M., Queenan, B., Susin, S.A. ( 2005) Programmed cell death via mitochondria: different modes of dying. Biochemistry (Mosc) 70: 231- 239.

Braun, B.R., Head, W.S., Wang, M.X., Johnson, A.D. ( 2000) Identification and characterization of TUP1-regulated genes in Candida albicans. Genetics 156: 31- 44. 
Burke, Y.D., Stark, M.J., Roach, S.L., Sen, S.E., Crowell, P.L. ( 1997) Inhibition of pancreatic cancer growth by the dietary isoprenoids farnesol and geraniol. Lipids 32: 151- 156.

Chakrabarti, R., Engleman, E.G. ( 1991) Interrelationships between mevalonate metabolism and the mitogenic signaling pathway in T lymphocyte proliferation. J Biol Chem 266: 12216- 12222.

Chen, C., Dickman, M.B. ( 2005) Proline suppresses apoptosis in the fungal pathogen Colletotrichum trifolii. Proc Natl Acad Sci USA 102: 3459-3464.

Cheng, J., Park, T.S., Chio, L.C., Fischl, A.S., Ye, X.S. ( 2003) Induction of apoptosis by sphingoid long-chain bases in Aspergillus nidulans. Mol Cell Biol 23: 163- 177.

Edwards, P.A., Ericsson, J. ( 1999) Sterols and isoprenoids: signaling molecules derived from the cholesterol biosynthetic pathway. Annu Rev Biochem 68: 157- 185.

Harris, S.D., Morrell, J.L., Hamer, J.E. ( 1994) Identification and characterization of Aspergillus nidulans mutants defective in cytokinesis. Genetics 136: 517- 532.

Harris, S.D., Read, N.D., Roberson, R.W., Shaw, B., Seiler, S., Plamann, M., Momany, M. ( 2005) Polarisome meets spitzenkorper: microscopy, genetics, and genomics converge. Eukaryot Cell 4: 225- 229.

Haug, J.S., Goldner, C.M., Yazlovitskaya, E.M., Voziyan, P.A., Melnykovych, G. ( 1994) Directed cell killing (apoptosis) in human lymphoblastoid cells incubated in the presence of farnesol: effect of phosphatidylcholine. Biochim Biophys Acta 1223: 133- 140.

Hemmerlin, A., Bach, T.J. ( 2000) Farnesol-induced cell death and stimulation of 3-hydroxy-3-methylglutaryl-coenzyme A reductase activity in tobacco cv Bright Yellow-2 cells. Plant Physiol 123: 1257- 1268.

Hogan, D.A., Vik, A., Kolter, R. ( 2004) A Pseudomonas aeruginosa quorum-sensing molecule influences Candida albicans morphology. Mol Microbiol 54: 1212- 1223.

Hornby, J.M., Jensen, E.C., Lisec, A.D., Tasto, J.J., Jahnke, B., Shoemaker, R. , et al. ( 2001) Quorum sensing in the dimorphic fungus Candida albicans is mediated by farnesol. Appl Environ Microbiol 67: 2982- 2992.

Hornby, J.M., Kebaara, B.W., Nickerson, K.W. ( 2003) Farnesol biosynthesis in Candida albicans: cellular response to sterol inhibition by zaragozic acid B. Antimicrob Agents Chemother 47: 2366- 2369.

Jillson, O.F., Nickerson, W.J. ( 1948) Mutual antagonism between pathogenic fungi. Inhibition of dimorphism in Candida albicans. Mycologia 40: 369-385.

Kafer, E. ( 1977) Meiotic and mitotic recombination in Aspergillus and its chromosomal aberrations. Adv Genet 19: 33131.

Kroemer, G., Martin, S.J. ( 2005) Caspase-independent cell death. Nat Med 11: 725- 730.

Kullberg, B.J., Filler, S.G. ( 2002) Candidemia. In Candida and Candidiasis. Calderone, R.A. (ed.). Washington, DC: American Society for Microbiology Press, pp. 327-340.

Langfelder, K., Streibel, M., Jahn, B., Haase, G., Brakhage, A.A. ( 2003) Biosynthesis of fungal melanins and their importance for human pathogenic fungi. Fungal Genet Biol 38: $143-158$.
LeBel, C.P., Ischiropoulos, H., Bondy, S.C. ( 1992) Evaluation of the probe 2',7'-dichlorofluorescin as an indicator of reactive oxygen species formation and oxidative stress. Chem Res Toxicol 5: 227- 231.

Leiter, E., Szappanos, H., Oberparleiter, C., Kaiserer, L., Csernoch, L., Pusztahelyi, T. , et al. ( 2005) Antifungal protein PAF severely affects the integrity of the plasma membrane of Aspergillus nidulans and induces an apoptosis-like phenotype. Antimicrob Agents Chemother 49: 2445- 2453.

Lewis, G.M., Hooper, M.E. ( 1943) Concurrent, combined, and consecutive fungous infections of the skin. Arch Derm Syph 47: 27- 35.

Liebmann, B., Gattung, S., Jahn, B., Brakhage, A.A. ( 2003) cAMP signaling in Aspergillus fumigatus is involved in the regulation of the virulence gene $p k s P$ and in defense against killing by macrophages. Mol Genet Genomics 269: 420- 435 .

Lo, H.J., Kohler, J.R., DiDomenico, B., Loebenberg, D., Cacciapuoti, A., Fink, G.R. ( 1997) Nonfilamentous C. albicans mutants are avirulent. Cell 90: 939- 949.

Ludovico, P., Rodrigues, F., Almeida, A., Silva, M.T., Barrientos, A., Corte-Real, M. ( 2002) Cytochrome c release and mitochondria involvement in programmed cell death induced by acetic acid in Saccharomyces cerevisiae. Mol Biol Cell 13: 2598- 2606.

Machida, K., Tanaka, T. ( 1999) Farnesol-induced generation of reactive oxygen species dependent on mitochondrial transmembrane potential hyperpolarization mediated by $F(0) F(1)-A T P a s e$ in yeast. FEBS Lett 462: 108- 112.

Machida, K., Tanaka, T., Fujita, K., Taniguchi, M. ( 1998) Farnesol-induced generation of reactive oxygen species via indirect inhibition of the mitochondrial electron transport chain in the yeast Saccharomyces cerevisiae. J Bacteriol 180: 4460- 4465.

Machida, K., Tanaka, T., Yano, Y., Otani, S., Taniguchi, M. ( 1999) Farnesol-induced growth inhibition in Saccharomyces cerevisiae by a cell cycle mechanism. Microbiology 145 ( Part 2): 293- 299.

Madeo, F., Frohlich, E., Frohlich, K.U. ( 1997) A yeast mutant showing diagnostic markers of early and late apoptosis. J Cell Biol 139: 729- 734.

Madeo, F., Frohlich, E., Ligr, M., Grey, M., Sigrist, S.J., Wolf, D.H., Frohlich, K.U. ( 1999) Oxygen stress: a regulator of apoptosis in yeast. J Cell Biol 145: 757- 767.

Madeo, F., Herker, E., Wissing, S., Jungwirth, H., Eisenberg, T., Frohlich, K.U. ( 2004) Apoptosis in yeast. Curr Opin Microbiol 7: 655- 660 .

Mendes-Giannini, M.J., Taylor, M.L., Bouchara, J.B., Burger, E., Calich, V.L., Escalante, E.D. , et al. ( 2000) Pathogenesis II: fungal responses to host responses: interaction of host cells with fungi. Med Mycol 38 ( Suppl. 1): 113- 123.

di Menna, M.E. ( 1955) A search for pathogenic species of yeasts in New Zealand soils. J Gen Microbiol 12: 54- 62.

Morris, N.R. ( 1975) Mitotic mutants of Aspergillus nidulans. Genet Res 26: 237- 254.

Mosel, D.D., Dumitru, R., Hornby, J.M., Atkin, A.L., Nickerson, K.W. ( 2005) Farnesol concentrations required to block 
germ tube formation in Candida albicans in the presence and absence of serum. Appl Environ Microbiol 71: 49384940.

Moss, J.E., Idanpaan-Heikkila, I., Zychlinsky, A. ( 2005) Induction of apoptosis by microbial pathogens. In Cellular Microbiology. Cossart, P.E.A. (ed.).

Washington, DC: American Society for Microbiology Press, pp. 409- 423.

Mousavi, S.A., Robson, G.D. ( 2004) Oxidative and amphotericin B-mediated cell death in the opportunistic pathogen Aspergillus fumigatus is associated with an apoptotic-like phenotype. Microbiology 150: 1937- 1945.

Oakley, B.R., Osmani, S.A. ( 1993) Cell cycle analysis using the filamentous fungus Aspergillus nidulans. In The Cell Cycle: A Practical Approach. Fantes, P., Brooks, R. (eds). Oxford: Oxford University Press, pp. 127- 142.

O'Connell, M.J., Osmani, A.H., Morris, N.R., Osmani, S.A. ( 1992) An extra copy of nimE ${ }^{\text {cyclinB }}$ elevates pre-MPF levels and partially suppresses mutation of nim $\mathrm{T}^{\mathrm{cdc} 25}$ in Aspergillus nidulans. EMBO J 11: 2139-2149.

Ramage, G., Saville, S.P., Wickes, B.L., Lopez-Ribot, J.L. ( 2002) Inhibition of Candida albicans biofilm formation by farnesol, a quorum-sensing molecule. Appl Environ Microbiol 68: 5459- 5463.

Rioja, A., Pizzey, A.R., Marson, C.M., Thomas, N.S. ( 2000) Preferential induction of apoptosis of leukaemic cells by farnesol. FEBS Lett 467: 291- 295.
Rosen, S., Yu, J.H., Adams, T.H. ( 1999) The Aspergillus nidulans sfaD gene encodes a $G$ protein beta subunit that is required for normal growth and repression of sporulation. EMBO J 18: 5592- 5600.

Saville, S.P., Lazzell, A.L., Monteagudo, C., Lopez-Ribot, J.L. ( 2003) Engineered control of cell morphology in vivo reveals distinct roles for yeast and filamentous forms of Candida albicans during infection. Eukaryot Cell 2: 1053- 1060.

Tateda, K., Ishii, Y., Horikawa, M., Matsumoto, T., Miyairi, S., Pechere, J.C. , et al. ( 2003) The Pseudomonas aeruginosa autoinducer N-3-oxododecanoyl homoserine lactone accelerates apoptosis in macrophages and neutrophils. Infect Immun 71: 5785- 5793.

Voziyan, P.A., Haug, J.S., Melnykovych, G. ( 1995) Mechanism of farnesol cytotoxicity: further evidence for the role of PKC-dependent signal transduction in farnesol-induced apoptotic cell death. Biochem Biophys Res Commun 212: 479- 486.

Waksman, S.A. ( 1941) Antagonistic relations of microorganisms. Bacteriol Rev 5: 231- 291.

Wu, J., Glass, N.L. ( 2001) Identification of specificity determinants and generation of alleles with novel specificity at the het-c heterokaryon incompatibility locus of Neurospora crassa. Mol Cell Biol 21: 1045- 1057.

Yu, J.H., Wieser, J., Adams, T.H. ( 1996) The AspergillusFIbA RGS domain protein antagonizes $G$ protein signalling to block proliferation and allow development. EMBO J 15: 5184- 5190 . 


\section{Supplementary material}

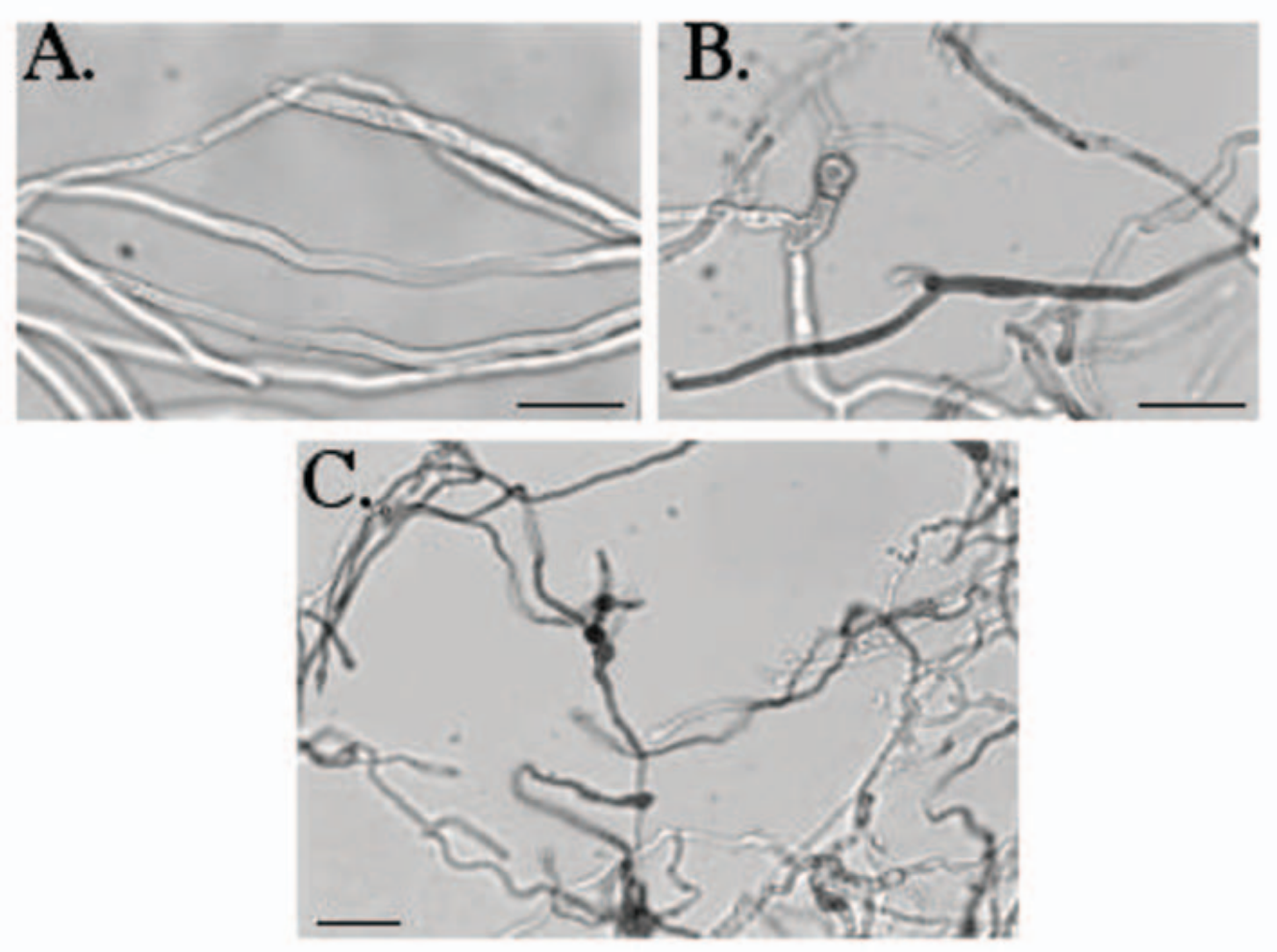

Figure S1. Farnesol treatment causes the death of hyphal cells. Spores of wild-type strain A28 were germinated on coverslips in YGV for $12 \mathrm{~h}$ at $30^{\circ} \mathrm{C}$, followed by treatment with 0 (A) and $100 \mathrm{uM}$ farnesol (B and C) for $2 \mathrm{~h}$. Hyphae were stained with Evan's Blue (1\%) for 5 minutes followed by 3 washes with PBS. Slides were examined under bright-field illumination from an Olympus BX51 fluorescent microscope. Darkened hyphal regions correspond to dead cells stained with Evan's Blue. Bars, 10 um. 


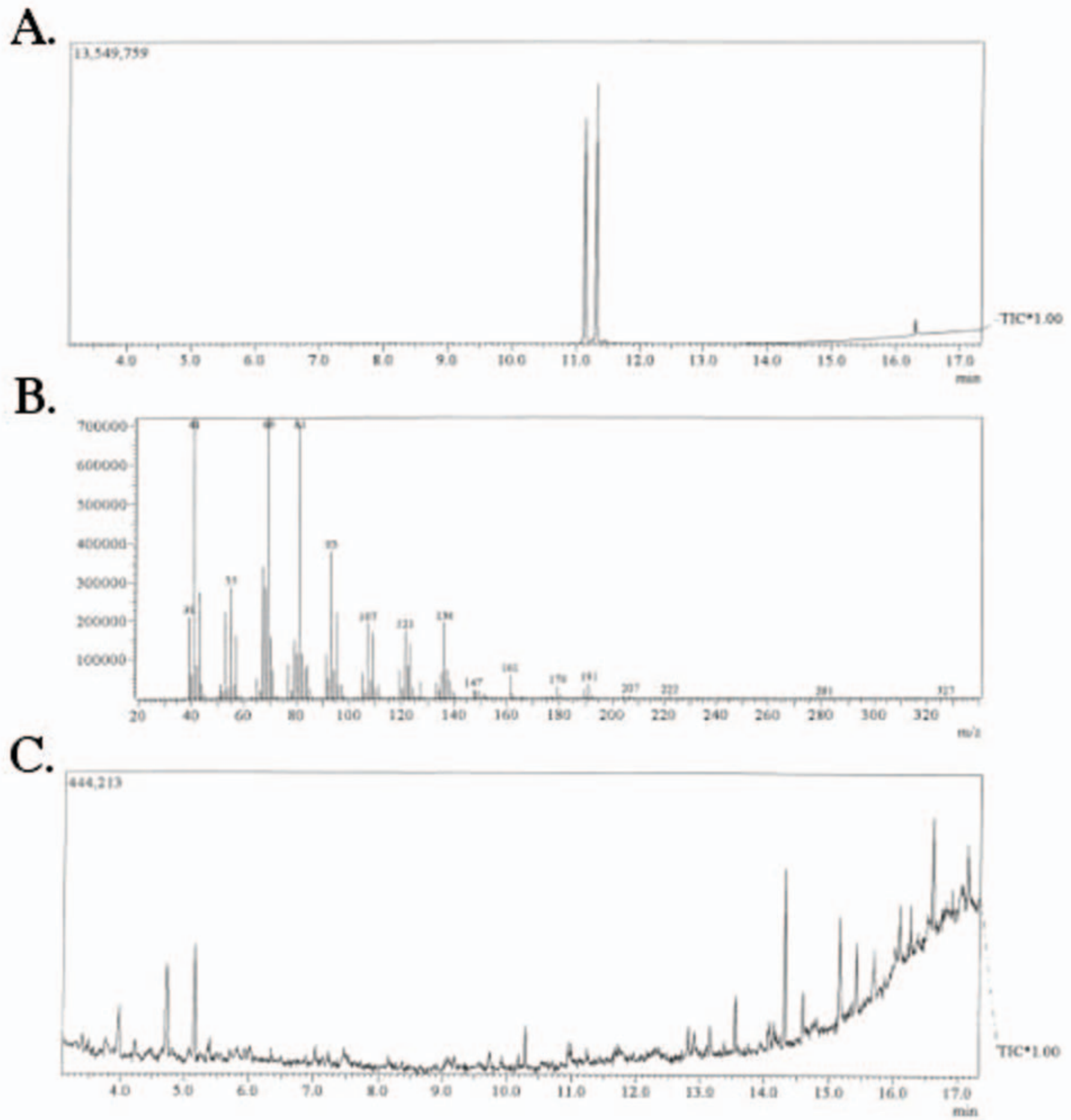

Figure S2. Aspergillus nidulans. A. nidulans wild-type A28 strain was grown in liquid media at $30^{\circ} \mathrm{C}$ and $200 \mathrm{rpm}$ for $24 \mathrm{~h}$. Cellfree supernatants were extracted and analyzed by gas chromatography/mass spectroscopy (GC/MS).

(A) GC analysis of a commercial sample of farnesol (mixed isomers, Sigma, St. Louis) showing two peaks A at 11.15 min and B at $11.32 \mathrm{~min}$, which represent two isomers.

(B) MS (El mode) fragmentation pattern of peak B showing the farnesol characteristic band at $\mathrm{m} / \mathrm{z} 69$.

(C) GC of the A28 culture supernatant showing no spectra resembling farnesol or related compounds. 


\section{Concentration} (vol/vol ratio)

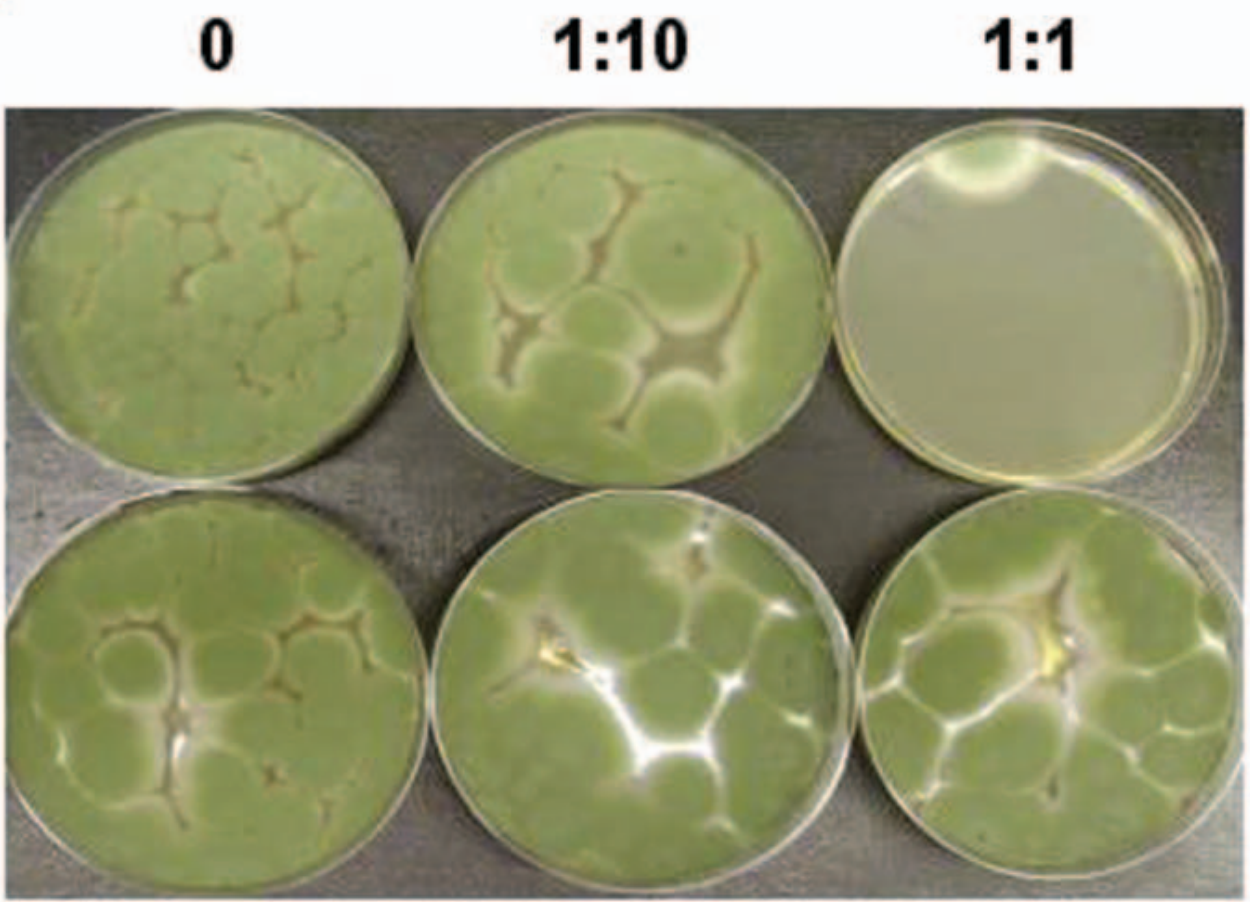

\section{Heat-Inactivated Conditioned media}

Figure S3. Aspergillus nidulans. A. nidulans A28 strain was inoculated into GPP media containing conditioned media obtained from a C. albicans A72 culture. As a control, part of conditioned media was autoclaved $\left(121^{\circ} \mathrm{C}\right.$ for 20 minutes) to heat inactivate farnesol. Amounts of conditioned media added were such as to give final concentrations of $0,1: 10$ and 1:1 vol/vol ratio. After incubation at $30^{\circ} \mathrm{C}, 200 \mathrm{rpm}$ for $24 \mathrm{~h}$, the cultures were washed, diluted, and plated onto solid YGV and incubated at $30^{\circ} \mathrm{C}$ for 3 days. 